\title{
High INDO (indoleamine 2,3-dioxygenase) mRNA level in blasts of acute myeloid leukemic patients predicts poor clinical outcome
}

\author{
Martine E.D. Chamuleau, ${ }^{1}$ Arjan A. van de Loosdrecht, ${ }^{1}$ Corine J. Hess, ${ }^{1}$ Jeroen J.W.M. Janssen, ${ }^{1}$ \\ Adri Zevenbergen, ${ }^{1}$ Ruud Delwel, ${ }^{2}$ Peter J.M. Valk, ${ }^{2}$ Bob Löwenberg, ${ }^{2}$ and Gert J. Ossenkoppele ${ }^{1}$ \\ ${ }^{1}$ Department of Hematology, VU University Medical Centre, Amsterdam; ${ }^{2}$ Department \\ of Hematology, Erasmus University Medical Centre, Rotterdam, the Netherlands
}

\section{ABSTRACT}

Indoleamine 2,3-dioxygenase degrades the amino acid tryptophan which is essential for T cells. Tryptophan depletion causes T-cell cycle arrest and solid tumors that express high levels of indoleamine 2,3-dioxygenase can create immune suppression. Recently, blasts of patients with acute myeloid leukemia were shown to express indoleamine 2,3-dioxygenase. We determined INDO (encoding gene for indoleamine 2,3-dioxygenase) mRNA expression in leukemic blasts of 286 patients with acute myeloid leukemia by gene-expression profiling. Results were validated by quantitative polymerase chain reaction analysis in blasts of an independent cohort of 71 patients. High INDO expression was correlated to significantly shortened overall and relapse-free survival. Correlation of INDO expression to relevant known prognostic factors and survival identified high INDO expression as a strong negative independent predicting variable for overall and relapse-free survival. Inhibition of indoleamine 2,3-dioxygenase expressed by myeloid leukemic blasts may result in breaking immune tolerance and offers new therapeutic options for patients with acute myeloid leukemia.

Key words: indoleamine 2,3-dioxygenase, INDO, acute myeloid leukemia, immunesurveillance, immune-therapy.

Citation: Chamuleau MED, van de Loosdrecht AA, Hess CJ, Janssen JJWM, Zevenbergen A, Delwel R, Valk PJM, Löwenberg B and Ossenkoppele GJ. High INDO (indoleamine 2,3-dioxygenase) mRNA level in blasts of acute myeloid leukemic patients predicts poor clinical outcome. Haematologica 2008; 93:1894-1898. doi: 10.3324/haematol.13112

(C)2008 Ferrata Storti Foundation. This is an open-access paper.

\section{Introduction}

Successful immunotherapy requires not only the development of effector $T$ cells, but also the break-through of the local state of immune tolerance that tumors can create. Besides several cellular and soluble factors (like the presence of regulatory $\mathrm{T}$ cells and transforming growth factor $\beta$ ), ${ }^{1}$ overexpression of the enzyme indoleamine 2,3-dioxygenase can induce tolerance. Indoleamine 2,3-dioxygenase degrades the essential amino acid tryptophan into kynurenine. High levels of indoleamine 2,3-dioxygenase result in immune suppression because $\mathrm{T}$ cells undergo cell cycle arrest in G1 phase at low tryptophan levels. ${ }^{2}$ Moreover, kynurenine and its derivates are directly toxic for $\mathrm{T}$ cells. ${ }^{3}$ Biologically relevant indoleamine 2,3-dioxygenase to limit $\mathrm{T}$-cell activation ${ }^{4}$ is expressed by interferon- $\alpha$ stimulated antigen presenting cells, in lower intestinal epithelial cells in which non-pathogenic bacteria are frequently present, and in trophoblast cells in which it protects the fetus from attack by maternal cytotoxic T cells. ${ }^{5}$

Tumor induced overexpression of indoleamine 2,3-dioxygenase causes immune-suppression at two levels. First, inhibition of effective T-cell priming by antigen presenting cell derived indoleamine 2,3-dioxygenase has been demonstrated in tumor-draining lymph nodes. ${ }^{6}$ Second, the effector phase of an anti-tumor immune response is hampered because many human solid tumors themselves express indoleamine 2,3dioxygenase..$^{7-9}$

In acute myeloid leukemia, acquired mutations of the hematopoietic stem cells block differentiation. The result is accumulation of immature cells in the bone marrow and peripheral blood, often accompanied by suppression of the normal blood cells. With chemotherapy and stem cell transplantation about $70 \%$ of patients achieve complete remission but approximately half of these patients relapse from the status of minimal residual disease. ${ }^{10}$ The immune system as surveillant in acute myeloid leukemia is unlikely to play a role at the moment of diagnosis (when an enormous tumor burden exists) but this is more likely during the period of minimal residual disease (when the patient has achieved morphological complete remission). We hypothesize that, in this phase of the disease, overexpression of indoleamine 2,3-dioxygenase by myeloid leukemic blasts could hamper immunesurveillance resulting in immune escape and shortened relapse-free and overall survival. With regard to hematologic malignancies, Curti et al. reported active indoleamine 2,3-dioxygenase protein in $52 \%$ of acute myeloid leukemic samples. ${ }^{11}$ They

Acknowledgments: we thank L. Pilotte and B.J. van den Eynde (Ludwig Institute, Brussels, Belgium) for kindly providing the IDO positive LB1610 cell line. Manuscript received March 25, 2008. Revised version arrived August 1, 2008. Manuscript accepted August 5, 2008.

Correspondence: Martine E.D. Chamuleau, MD, Department of Hematology, VU University Medical Centre, De Boelelaan 1117, 1081 HV Amsterdam,

The Netherlands. E-mail: m.chamuleau@vumc.nl 
also clearly demonstrated that indoleamine 2,3-dioxygenase expressed by human myeloid leukemic cells induces the expansion of $\mathrm{CD}^{+}{ }^{+} \mathrm{CD} 25^{+} \mathrm{FOXP3}^{+}$regulatory $\mathrm{T}$ cells in mice. ${ }^{12}$ These data presume an important role for indoleamine 2,3-dioxygenase in immune escape. However, negative influence of high indoleamine 2,3-dioxygenase expression on overall survival of patients has only been demonstrated for endometrial and colorectal cancer. ${ }^{8.9}$ In the present study we investigated whether the expression of INDO (the gene encoding for indoleamine 2,3-dioxygenase) correlates to clinical outcome of patients with acute myeloid leukemia. We determined INDO expression in myeloid leukemic blasts of 285 patients by gene-expression analyses and in 71 patients by real-time quantitative polymerase chain reaction (qPCR) and correlated these data to relevant known prognostic factors and survival.

\section{Design and Methods}

\section{Patients' characteristics}

After informed consent and according to the recommendations as defined in the declaration of Helsinki in 1989, bone marrow derived samples were collected from patients with primary acute myeloid leukemia. Patients were classified according to the FrenchAmerican-British (FAB) classification. ${ }^{13}$ Clinical characteristics of the patients that were selected for geneexpression profiling analysis have been previously described $^{14}$ and shown in Table 1. For patients analyzed by qPCR, clinical characteristics are comparable to the clinical characteristics of patients that were analyzed by gene-expression profiling (Table 1).

Cytogenetic risk group was defined as favorable $(\mathrm{t}(8 ; 21)$, inv(16) or $\mathrm{t}(15 ; 17))$, standard (neither favorable nor adverse) or adverse (complex karyotype, -5, -7, $\operatorname{del}(5 q), \operatorname{del}(7 q), \operatorname{abn}(3 q), t(6 ; 9)$ or abn (11q23)).

Patients of both groups received therapy according to HOVON (Dutch-Belgian Hematology-Oncology Cooperative Group) protocols. Most patients received 2 cycles of chemotherapy (containing cytarabin combined with idarubicin or amsacrine) followed by an autologous stem cell transplantation or a third cycle of chemotherapy (mitoxantrone and etoposide). Only 3 patients received allogeneic stem cell transplantation. Protocols are available at $w$ ww. hovon.nl. Overall survival was defined as the time period from inclusion to death or last date of follow-up; relapse-free survival was defined as the time period from achievement of complete remission to relapse.

\section{Sample characteristics}

Blood and bone marrow derived mononuclear cell fractions from patients with primary acute myeloid leukemia were obtained by Ficoll centrifugation (purity of blasts $>80 \%$ ), cryopreserved and used for geneexpression profiling. For $\mathrm{qPCR}$ analysis, $7 \mathrm{AAD}^{-/} \mathrm{An}-$ nexinV $V^{-} / \mathrm{CD}^{2} 5^{\text {dim }}$ cells from patients with primary acute myeloid leukemia were FACS sorted after thawing (purity of blasts $>95 \%$ ). For comparison, bone marrow from 5 healthy donors was withdrawn and $7 \mathrm{AAD}^{-} / \mathrm{An}-$
Table 1. Comparison of clinical characteristics of patients with acute myeloid leukemia whose blasts were analyzed for INDO expression by gene-expression profiling and by qPCR.

\begin{tabular}{|c|c|c|}
\hline Type of analysis & Gene-expression profiling & $q P C R$ \\
\hline Number & 286 & 71 \\
\hline $\begin{array}{l}\text { Median age in years } \\
\text { at diagnosis (range) }\end{array}$ & $44(15-78)$ & $54(16-75)$ \\
\hline $\begin{array}{l}\text { Median white blood cell count } \\
\text { at diagnosis }\left(10 x^{9} / L \text {, range }\right)\end{array}$ & $28(0.3-582)$ & $42(0.4-282)$ \\
\hline $\begin{array}{l}\text { Complete remission rate, } \\
\text { number }(\%)\end{array}$ & 203 (79.6) & $55(78)$ \\
\hline $\begin{array}{l}\text { Median overall survival } \\
\text { in months (range) }\end{array}$ & $13(0-166)$ & $14.4(0.03-174)$ \\
\hline $\begin{array}{l}\text { Median relapse free survival } \\
\text { in months (range) }\end{array}$ & $11(0-166)$ & $16.6(0.23-173)$ \\
\hline \multicolumn{3}{|l|}{ FAB classification, number (\%) } \\
\hline AML MO & $6(2)$ & $4(6)$ \\
\hline AML M1 & $63(22)$ & $9(13)$ \\
\hline AML M2 & $66(23)$ & $20(19)$ \\
\hline AML M3 & $19(7)$ & $3(4)$ \\
\hline AML M4 & 53 (19) & $12(17)$ \\
\hline AML M5 & $65(23)$ & $20(28)$ \\
\hline AML M6 & $3(1)$ & $3(4)$ \\
\hline not determined & $10(3)$ & \\
\hline \multicolumn{3}{|c|}{ Cytogenetic risk group, number (\%) } \\
\hline Favorable & $57(20)$ & $4(6)$ \\
\hline Standard & $176(62)$ & $40(56)$ \\
\hline Adverse & $39(14)$ & $6(9)$ \\
\hline No metaphasis & $13(4)$ & $6(9)$ \\
\hline Not done & & $15(21)$ \\
\hline \multicolumn{3}{|l|}{ FLT3 status, number (\%) } \\
\hline FLT3 ITD pos & $78(27)$ & $19(27)$ \\
\hline FLT3 ITD neg & $207(73)$ & $52(73)$ \\
\hline FLT3 TKD pos & $33(12)$ & $5(7)$ \\
\hline FLT3 TKD neg & $252(88)$ & $66(93)$ \\
\hline
\end{tabular}

nexinV $/ \mathrm{CD}^{\mathrm{dim}}$ normal blasts (purity $>95 \%$ ) were FACS sorted.

\section{Gene-expression profiling and real-time $q P C R$}

Gene-expression levels for INDO were determined by using Affymetrix U133A GeneChips ${ }^{14}$ (Affymetrix-id for INDO 210029_at, M34455 NCBI). For qPCR, RNA was isolated using RNA-Bee solution (Tel-Test Inc, Friendswood, TX, USA). Total RNA was stored at $-80^{\circ} \mathrm{C}$. cDNA synthesis was performed according to a standardized Europe Against Cancer protocol. ${ }^{15}$ PCR amplification was performed with a LightCycler real-time PCR machine (Roche Diagnostics, Almere, the Netherlands). Reaction volumes were $20 \mu \mathrm{L}$, consisting of $2 \mu \mathrm{L}$ cDNA, $2 \mu \mathrm{L}$ of LightCycler Fast Start DNA SYBR Green Mastermix (Roche) and $0.5 \mu \mathrm{M}$ reverse and forward primers. $\mathrm{MgCl}_{2}$ was added to a final concentration of $3.5 \mu \mathrm{M}$ (for GUS $4 \mu \mathrm{M}$ ). qPCR conditions consisted of an initial denaturation step at $95^{\circ} \mathrm{C}$ for $10 \mathrm{~min}$, followed by 45 cycles, each for $15 \mathrm{sec}$ at $95^{\circ} \mathrm{C}, 10 \mathrm{sec}$ at $58^{\circ} \mathrm{C}$ (for GUS $59^{\circ} \mathrm{C}$ ) and $10 \mathrm{sec}$ at $72^{\circ} \mathrm{C}$. Relative quantitation of gene-expression was determined using the LB1610 cell line (see Acknowledgments). All results were normalized with respect to the $\beta$-glucuronidase (GUS) 
control. Primer sequences were: INDO forward: 5'GTGTTTCACCAAATCCACGA-3', reverse: 5'-CTGATAGCTGGGGGTTGC-3'; GUS forward: 5'-GAAAATATGTGGTTGGAGAGCTCATT-3', reverse: 5'CCGAGTGAAGATCCCCTTTTTA-3 (Biolegio BV, (Nijmegen, the Netherlands).

\section{Western blot}

For Western Blot analysis, human peripheral blood derived monocytes selected by magnetic separation (positive selection with CD14 microbeads, Miltenyi Biotec, Bergisch Gladbach, Germany) were used. Purity was greater than $97 \%$. Monocytes were incubated for 18 hours with interferon- $\alpha$. Snap frozen cells were prepared by resuspending in lysis buffer $(50 \mathrm{mM}$ Tris-HCl (pH 7.6), $5 \mathrm{mM}$ dithiotreitol, $20 \mu \mathrm{L}$ PIC (Protease Inhibitor Cocktail; 1 tablet $/ \mathrm{mL} \mathrm{H}_{2} \mathrm{O}$ ), $20 \%$ glycerol and $0.5 \%$ NP-40). Protein content of the supernatant was determined by the Bio-Rad protein assay. Twenty micrograms of total cell lysates were fractionated on a $12.5 \%$ polyacrylamide gel containing SDS and transferred onto a PVDF membrane. Indoleamine 2,3-dioxygenase was visualized by luminescence (ECL Kit, Amersham) using Hyperfilm ECL (Amersham) after incubation with anti-human indoleamine 2,3-dioxygenase antibody (clone 10.1, Chemicon, 1:1000) and horseradish peroxidase-coupled rabbit anti-mouse IgG. $\alpha$-tubulin was detected by incubation with a mouse anti-human $\alpha$-tubulin monoclonal antibody (Sc-5286 Santa Cruz) by luminescence as above.

\section{Statistical analysis}

Statistical analyses were conducted using a SPSS 12.0.1 software program. To determine associations between variables, Spearman's correlation coefficient was used. Differences between patients' characteristics were analyzed with the Mann-Whitney U test. For survival data, Kaplan-Meier curves were compared by means of the log-rank test. To explore the simultaneous effect of several variables on overall and relapse-free survival the Cox regression model was used.

\section{Results and Discussion}

Two hundred and eighty-six patients were analyzed for the expression of INDO by gene-expression profiling. INDO mRNA expression was variable and not significantly associated with any one of the 16 subtypes of acute myeloid leukemia, which were identified on their specific gene-expression signatures, ${ }^{14}$ presuming independency of these prognostic clusters (Figure 1A). Moreover, no significant differences were found between INDO mRNA expression of different FAB subtypes and cytogenetic risk profiles. Correlation of INDO expression to survival data of 262 patients revealed that all patients with prolonged overall survival had low INDO expression. We decided to validate these data by qPCR. Correlation between microarray and qPCR is generally strong, although there is non-concordance in $13-16 \%$ of genes. ${ }^{16}$ INDO mRNA expression levels relative to GUS by qPCR nicely correlated to protein levels as determined by Western blot on human peripheral blood interferon- $\alpha$ stimulated monocytes (Figure 1B). We then determined INDO mRNA expression levels in 71 patients and 5 healthy donors. INDO expression relative to GUS in blasts of healthy donors was low (mean 0.538 , median 0.32 , range 0.06-1.18). INDO expression relative to GUS in blasts of patients with acute myeloid leukemia was highly variable, but mean and median expression was higher (mean 5.68, median 0.51, range $0-304)$ than INDO expression in blasts of healthy donors.

As in the patient group analyzed by gene-expression profiling, no significant differences in INDO expression analyzed by qPCR were found between FAB subtypes and cytogenetic risk groups. As the white blood cell count in this patient group was high (median $42 \times 10^{9} / \mathrm{L}$ ) and FLT3 (fms-related tyrosine kinase 3) mutations are frequently found in patients with a high white blood cell count, we also analyzed FLT3 internal tandem duplication (ITD) and tyrosine kinase domain (TKD) mutations, but INDO expression was not significantly different in patients with the mutations of FLT3 (mean INDO expression: FLT3-ITD positive patients 11.5, FLT3-ITD negative patients 11.6).

When correlating INDO expression levels to clinical outcome, patients with prolonged overall survival had low INDO levels (Figure 1C). As the maximum INDO level in healthy donors was 1.2 relative to GUS, we divided the patients into 2 groups; those having INDO greater than $1.2(\mathrm{n}=15)$ or lower than or equal to 1.2 $(n=56)$. There was no difference in median age and white blood cell counts at diagnosis between these groups. However, patients with INDO level $>1.2$ had a significantly decreased overall survival as compared to patients with INDO level lower than 1.2 [7.4 months vs. 21.4 months respectively, $p=0.01$ (Mann-Whitney U)]. Also, relapse-free survival was significantly shortened in patients with INDO level gretear than 1.2 as compared to patients with INDO level lower than 1.2 (6.1 months vs. 24.5 months respectively, $p=0.025$ (Mann-Whitney U)). Note that other cut-off levels such as 0.5 (median of healthy controls) or 1.5 resulted in comparable significant results. INDO expression more or less than 1.2 resulted in strongly diverging Kaplan Meier survival curves for overall and relapse-free survival (Figures 1D and $1 \mathrm{E})$.

In a univariate regression model, INDO expression level greater than 1.2 was the strongest predictor for overall survival ( $p<0.001$ odds ratio 3.2$)$, as compared to white blood cell count ( $p=0.038$, odds ratio 1.004), age $(p=0.012$, odds ratio 1.019) and FLT3-ITD mutation $(p=0.058$, odds ratio 1.8). In a multivariate regression model with the same variables, INDO expression level greater than 1.2 remained the strongest independent factor predicting survival ( $p=0.001$ vs. $p=0.29$ (white blood cell count), $p=0.005$ (age) and $p=0.055$ (FLT3-ITD mutation).

As the groups of patients with good and poor cytogenetic risk profile were too small to use in a multiple regression model, the group with an intermediate cytogenetic risk profile was analyzed $(n=40)$. Also in this group INDO expression was a strong predictor for sur- 

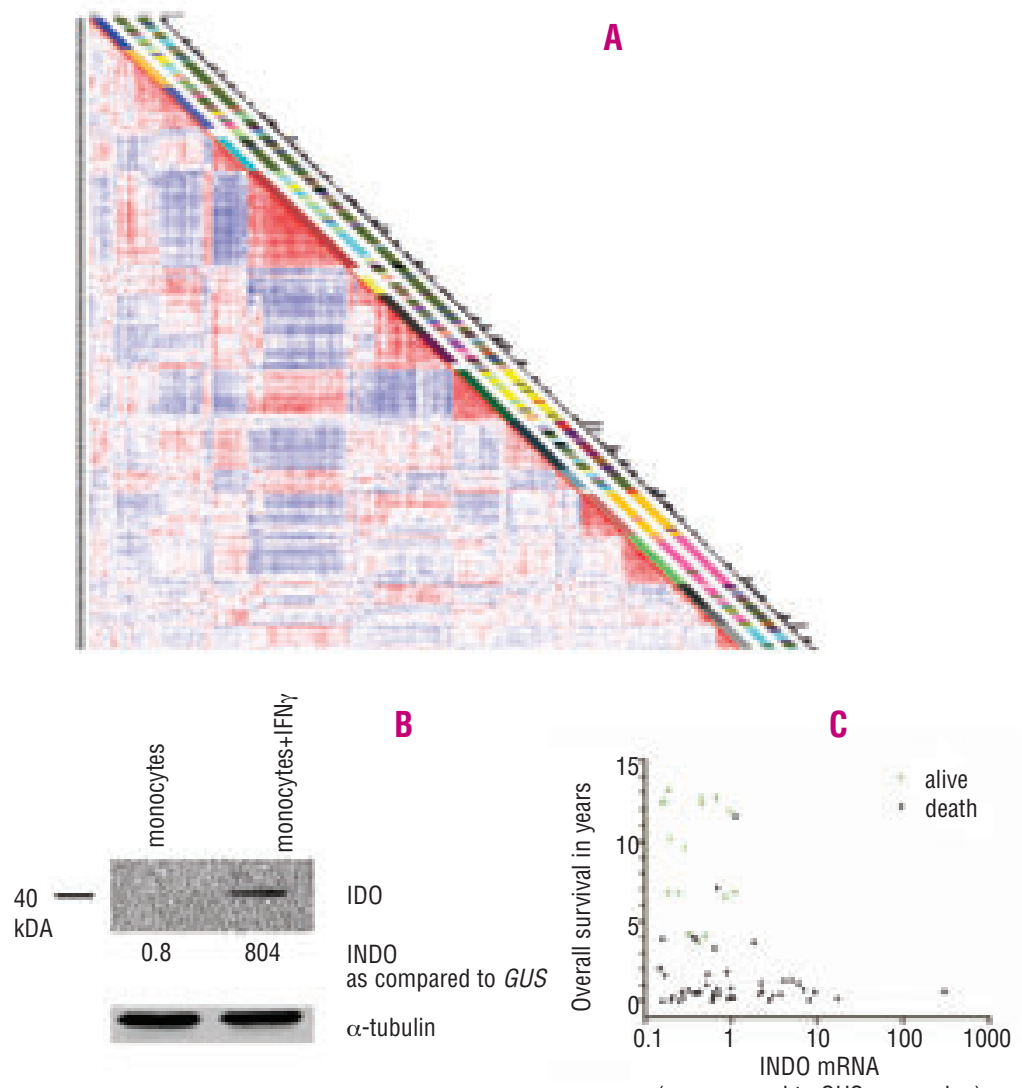

(as compared to GUS expression)
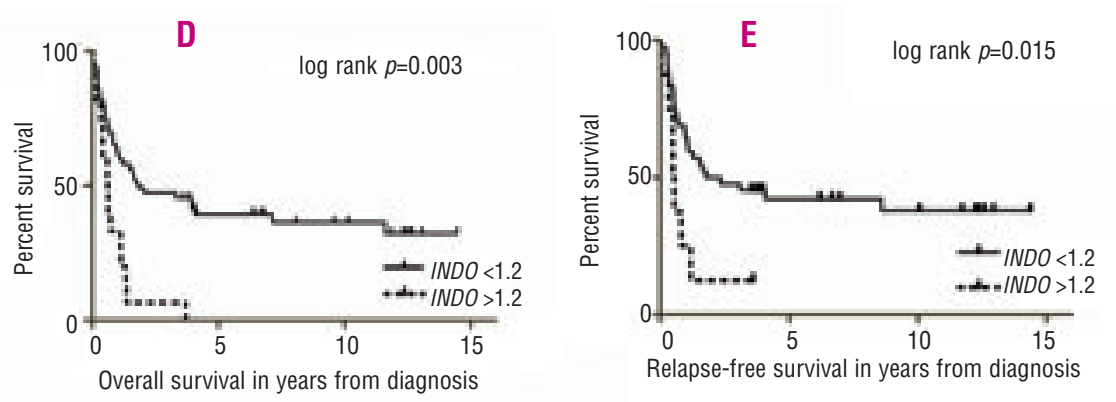

Figure 1. (A) INDO expression by microarray and by QPCR correlated to clinical outcome. Unsupervised cluster analyses on the basis of gene-expression profiles of 285 blasts of patients with acute myeloid leukemia. The columns adjacent to the heatmap indicate sample characteristics (column 1: the 16 gene-expression cluster (distinct colors 1-16); column 2: FAB (M0-red, M1-green, M2-purple, M3-orange, M4-yellow, M5-blue, M6grey); column 3: karyotype (normalgreen, inv(16)-yellow, $t(8 ; 21)$-purple, $\mathrm{t}(15 ; 17)$-orange, $11 \mathrm{q} 23$ abnormalitiesblue, 7(q) abnormalities-red, +8-pink, complex-black, other-gray)); column 4: INDO mRNA expression (probe set ID 210029_at, size of histogram proportional to level of expression). INDO expression does not correlate to one of the 16 previously described gene-expression subgroups ${ }^{14}$ the $\mathrm{FAB}$ classification or karyotype of the acute myeloid leukemia cases. (B) INDO mRNA expression levels (relative to GUS) by GPCR nicely correlated to protein levels of indoleamine 2,3-dioxygenase (IDO) as determined by Western Blot on human peripheral blood interferon- $\gamma$ (IFN- $\gamma$ ) stimulated monocytes. (C) INDO expression analyzed by qPCR in 71 patients with acute myeloid leukemia. Patients with prolonged overall survival have low INDO expression level. D. and E. INDO expression levels analyzed by qPCR; INDO expression >1.2 (relative to GUS) correlates to significantly shortened overall and relapse-free survival ( $x$ - axis is log transformed). vival ( $p=0.009$, odds ratio 1.146). Myeloid leukemic blasts do express an active form of indoleamine 2,3dioxygenase protein as previously demonstrated in human myeloid leukemic samples and in vivo in mice. ${ }^{11,12}$ Moreover, Curti et al. demonstrated good correlation between INDO mRNA level, indoleamine 2,3-dioxygenase protein expression levels and function in myeloid leukemic samples.

Our findings show that all patients with prolonged overall survival had low INDO expression levels and that high INDO expression levels were a strong negative predicting variable for worse outcome of patients with acute myeloid leukemia. In a multivariate regression model, a high INDO expression level was a stronger predicting variable than white blood cell count, age and FLT3-ITD mutational status.

High INDO expression was also significantly correlated to a lower complete remission rate $(53 \%$ for patients with INDO expression level greater than $1.2(p=0.01$ (Mann-Whitney U) versus $84 \%$ for patients with INDO expression level lower than $1.2, p=0.01$ (Mann-Whitney $U)$ ). This was surprising as it is not expected that the amount of indoleamine 2,3-dioxygenase in blasts is affecting drug sensitivity. In this study, we cannot exclude that high INDO expression is a part of a more complex phenotype associated with chemoresistance. However, when only analyzing patients that achieved complete remission, high INDO expression was correlated to shortened relapse-free survival.

In the treatment of patients with acute myeloid leukemia, there is a need for additional therapies to prevent relapse in patients that have achieved complete remission. The success of allogeneic stem cell transplantation has demonstrated clearly that immune surveillance plays a role by eradicating minimal residual leukemic cells resulting in prolonged complete remission rates for patients with acute myeloid leukemia. However, allogeneic stem cell transplantation is not available for many patients. For these patients, rehabilitation of autologous immune surveillance, for example 
by inhibition of tumor induced indoleamine 2,3-dioxygenase expression could offer new treatment possibilities. As inhibition of indoleamine 2,3-dioxygenase by orally available inhibitors like 1-methyl-tryptophan is effective in mice and synergistic with chemotherapy, ${ }^{17,18}$ we now provide further reason for rapid exploration of the introduction of indoleamine 2,3-dioxygenase inhibition in the treatment of patients with acute myeloid leukemia. Besides these opportunities for new immune modulating therapies, measuring INDO levels provides useful prognostic information, as a high INDO expression level is correlated to a lower complete remission rate, and shorter overall and relapse-free survival of patients with acute myeloid leukemia.

\section{Authorship and Disclosures}

MC performed experiments, analyzed results and wrote the paper; AvdL designed research; $\mathrm{CH}$ collected samples; JJ performed experiments and analyzed results; AZ performed experiments; $\mathrm{RD}$ and $\mathrm{PV}$ performed experiments and analyzed results; $\mathrm{BL}$ and $\mathrm{GO}$ designed research. The authors reported no potential conflicts of interest.

\section{References}

1. Gajewski TF, Meng Y, Harlin H. Immune suppression in the tumor microenvironment. J Immunother 2006;29:233-40.

2. Munn DH, Shafizadeh E, Attwood JT, Bondarev I, Pashine A, Mellor AL. Inhibition of $\mathrm{T}$ cell proliferation by macrophage tryptophan catabolism. J Exp Med 1999;189:1363-72.

3. Fallarino F, Grohmann U, Vacca C, Bianchi R, Orabona C, Spreca A, et al. T cell apoptosis by tryptophan catabolism. Cell Death Differ 2002; 9: 1069-77.

4. Mellor AL, Munn DH. IDO expression by dendritic cells: tolerance and tryptophan catabolism. Nat Rev Immunol 2004;4:762-74

5. Munn DH, Zhou M, Attwood JT, Bondarev I, Conway SJ, Marshall B, et al. Prevention of allogeneic fetal rejection by tryptophan catabolism. Science 1998;281:1191-3.

6. Munn DH, Sharma MD, Hou D, Baban B, Lee JR, Antonia SJ, et al. Expression of indoleamine 2,3-dioxygenase by plasmacytoid dendritic cells in tumor-draining lymph nodes. J Clin Invest 2004;114:280-90.

7. Uyttenhove C, Pilotte L, Theate I, Stroobant V, Colau D, Parmentier N, et al. Evidence for a tumoral immune resistance mechanism based on tryptophan degradation by indoleamine 2,3-dioxygenase. Nat Med 2003;9:
1269-74.

8. Ino K, Yoshida N, Kajiyama H, Shibata K, Yamamoto E, Kidokoro K, et al. Indoleamine 2,3-dioxygenase is a novel prognostic indicator for endometrial cancer. Br J Cancer 2006; 95 : 1555-61.

9. Brandacher G, Perathoner A, Ladurner R, Schneeberger S, Obrist P Winkler $C$, et al. Prognostic value of indoleamine 2,3-dioxygenase expression in colorectal cancer: effect on tumor-infiltrating T cells. Clin Cancer Res 2006;12:1144-51.

10. Lowenberg B, Downing JR, Burnett A. Acute myeloid leukemia. $\mathrm{N}$ Engl J Med 1999;341:1051-62.

11. Curti A, Aluigi M, Pandolfi S, Ferri E, Isidori A, Salvestrini V, et al. Acute myeloid leukemia cells constitutively express the immunoregulatory enzyme indoleamine 2,3-dioxygenase. Leukemia 2007:21:353-5.

12. Curti A, Pandolfi S, Valzasina B, Aluigi M, Isidori A, Ferri E, et al Modulation of tryptophan catabolism by human leukemic cells results in the conversion of CD25- into CD25+ $\mathrm{T}$ regulatory cells. Blood 2007;109:2871-7.

13. Bennett JM, Catovsky D, Daniel MT, Flandrin G, Galton DA, Gralnick HR, et al. Proposed revised criteria for the classification of acute myeloid leukemia. A report of the French-American-British Cooperative Group. Ann Intern Med 1985;103: 620-5.

14. Valk PJ, Verhaak RG, Beijen MA, Erpelinck CA, Barjesteh van Waal- wijk van Doorn-Khosrovani, Boer JM, et al. Prognostically useful geneexpression profiles in acute myeloid leukemia. N Engl J Med 2004;350: 1617-28.

15. Gabert J, Beillard E, van der Velden VH, Bi W, Grimwade D, Pallisgaard $\mathrm{N}$, et al. Standardization and quality control studies of 'real-time' quantitative reverse transcriptase polymerase chain reaction of fusion gene transcripts for residual disease detection in leukemia - a Europe Against Cancer program. Leukemia 2003;17: 2318-57.

16. Dallas $\mathrm{PB}$, Gottardo NG, Firth MJ, Beesley AH, Hoffmann K, Terry PA, et al. Gene expression levels assessed by oligonucleotide microarray analysis and quantitative real-time RTPCR - how well do they correlate? BMC Genomics 2005;6:59

17. Muller AJ, DuHadaway JB, Donover PS, Sutanto-Ward E, Prendergast GC. Inhibition of indoleamine 2,3-dioxygenase, an immunoregulatory target of the cancer suppression gene Bin1, potentiates cancer chemotherapy. Nat Med 2005;11:312-9.

18. Hou DY, Muller AJ, Sharma MD DuHadaway J, Banerjee T, Johnson $M$, et al. Inhibition of indoleamine 2,3-dioxygenase in dendritic cells by stereoisomers of 1-methyl-tryptophan correlates with antitumor responses. Cancer Res 2007;67:792801. 